\title{
Gain and Noise Figure Characteristic of EDFA by Four Stage Method
}

\author{
Samiksha Jain \\ Electronics \& Communication Department, \\ BIST, Bhopal MP, INDIA
}

\author{
Manish Saxena \\ Electronics \& Communication Department, \\ BIST, Bhopal MP, INDIA
}

\begin{abstract}
Fiber loss is a fundamental limitation in realizing long haul point-to-point fiber optical communication links and optical networks. One of the advanced technologies achieved in recent years is the advent of erbium doped fiber amplifiers (EDFAs) that has enabled the optical signals in an optical fiber to be amplified directly in high bit rate systems beyond Terabits. In this paper, an EDFA simulation program has been written in opt system to characterize Gain, Noise Figure and optical signal to noise ratio (OSNR). The four stage enhancement circuit has been designed and simulation studies for different types of pump power. Further, for the EDFA with comparatively better gain and noise figure spectrum, the pump powers are varied and a comparison of gain and noise figure with respect to wavelength is carried out
\end{abstract}

\section{Keywords}

Erbium Doped Fiber Amplifier (EDFA), Gain, Noise Figure, Optical Signal to Noise Ratio (OSNR)

\section{INTRODUCTION}

Communication is the process of transmitting and sharing of data or information or news from certain location to destination. In previous time People uses certain types of music instruments such as drums, Pigeon post, Hydraulic semaphores etc. to convey the information. But due to invent of science, communication can became a easy task as compare to previous era. It may also be described that communication is to sharing of idea between one people to another.

Nowadays we can't imagine the world without communication. The use of fiber optic communication emerges due to its low weight, high bandwidth, easy to maintain, low cost etc. Because of its wide variety of advantages fiber optic communication system has wide range of applications also. The fiber optic communication systems are used in telephones, internet services, cable television, closed circuit television, military applications etc. Although the communication system suffers from fiber loss, attenuation, dispersion, etc [1], [2] Optical amplifiers are used to overcome these limitations occurs in fiber optic communication systems. The optical amplifiers were developed in 1980s and commercially available in 1990s. The most significant types of optical amplifiers are Raman amplifier [3], semiconductor laser amplifier, Brillouin amplifiers and rare-earth doped fiber amplifiers. EDFA (Erbium doped fiber amplifier) is a special class of optical amplifier widely used today. EDFA has several parameters such as pump wavelength, pump power, signal wavelength, signal power, Erion density, Er-doping radius, Fiber length, Gain, Noise figure etc. Out of them the overall performance of fiber optic communication is mainly depends on the gainnoise figure values. The gainnoise figure are highly depends on the parameters like pump power, fiber length, Er-ion concentration etc. Here the low powered input signal along with high powered pump signal is fed to erbium doped fiber through an optical coupler. The pump energy is transferred to the signal by the process of stimulated emission. The pump can be used at either $980 \mathrm{~nm}$ or $1480 \mathrm{~nm}$. The signal wavelength shows better gain in the range of 1530$1560 \mathrm{~nm}$. The pump power always greater than $10 \mathrm{mw}$ to obtain good gain-noise figure values. The EDFA acts like an optical repeater. It amplifies the optical signal itself without ever changing it to electricity. For long haul point-to-point fiber optic communication without significant loss of power EDFA has become the best choice. We can achieve an optical gain upto $30 \mathrm{db}$, it means 1000 photons out per photon in. There should an optimum value of these parameters for better performance. The amplified optical signals are given to demodulators for optical to electrical conversion.

\section{EDFA DESIGN}

The simulation model in optisystem is shows in figure 1. Here the information signal and the pump signal are passed into the EDFA with sufficient Er-ion density through the coupler. The information signal is at $1552 \mathrm{~nm}$ and pump signal is at $2 \mathrm{~nm}$. Pump power is selected at $100 \mathrm{mw}$. Then simulate the output for different values of pump power. One more parameter that is strongly depends on the gain also considered, terms the fiber length. Then vary these parameters in a combined manner so that better gain, noise figure is obtained. 


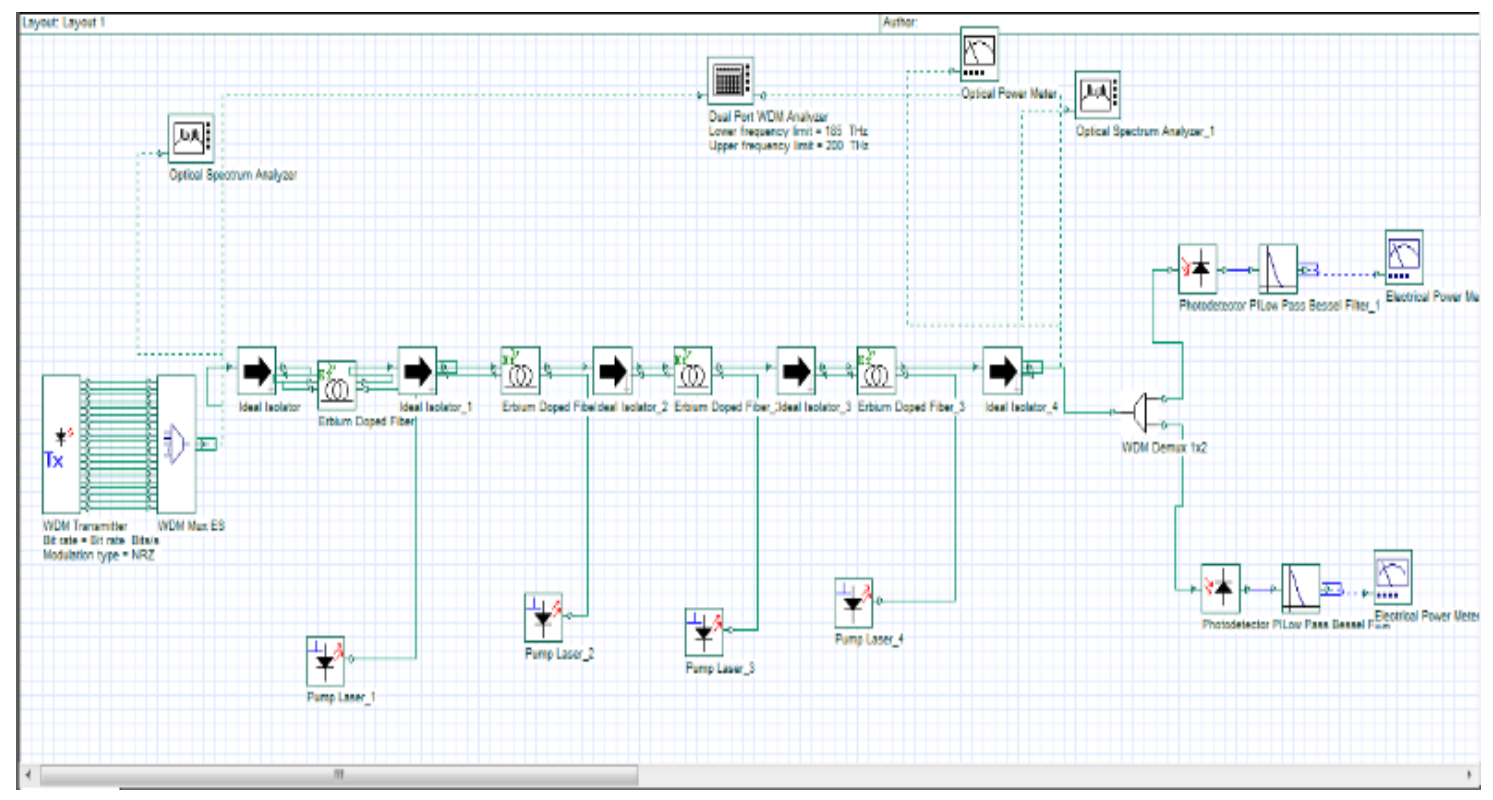

Figure 1: Four Stage EDFA Circuitry

\section{RESULTS AND DISCUSSION}

The dynamic response of the amplifier is obtained when switching from the red sub band channels to the blue sub band channel.

Table I: Gain Spectrum for different pump powers

\begin{tabular}{|c|c|c|c|c|}
\hline Wavelength & \multicolumn{4}{|c|}{ Gain dbm } \\
\hline $\mathrm{nm}$ & $\begin{array}{l}0.2 \mathrm{~W} \\
\text { pump } \\
\text { power }\end{array}$ & $\begin{array}{l}0.25 \mathrm{w} \\
\text { pump } \\
\text { power }\end{array}$ & $\begin{array}{l}0.5 \mathrm{w} \\
\text { pump } \\
\text { power }\end{array}$ & $\begin{array}{l}0.75 \mathrm{w} \\
\text { pump } \\
\text { power }\end{array}$ \\
\hline 1552 & 28.96 & 31.02 & 37.03 & 40.28 \\
\hline 1554 & 32.4 & 34.39 & 40.19 & 43.32 \\
\hline 1556 & 35.53 & 37.45 & 43.03 & 46.05 \\
\hline 1558 & 38.44 & 40.28 & 45.64 & 48.53 \\
\hline 1560 & 40.8 & 42.54 & 47.59 & 50.32 \\
\hline 1562 & 42.69 & 44.31 & 49.02 & 51.56 \\
\hline 1564 & 44 & 45.48 & 49.79 & 52.12 \\
\hline 1566 & 44.86 & 46.21 & 50.12 & 52.23 \\
\hline 1568 & 45.31 & 46.53 & 50.06 & 51.97 \\
\hline 1570 & 45.35 & 46.44 & 49.6 & 51.31 \\
\hline 1572 & 45.35 & 46.33 & 49.19 & 50.73 \\
\hline 1574 & 45.21 & 46.09 & 48.68 & 50.07 \\
\hline 1576 & 44.94 & 45.74 & 48.08 & 49.34 \\
\hline 1578 & 44.83 & 45.57 & 47.72 & 48.89 \\
\hline 1580 & 44.74 & 45.43 & 47.43 & 48.51 \\
\hline 1582 & 44.856 & 45.5 & 47.4 & 48.42 \\
\hline 1584 & 44.852 & 45.46 & 47.25 & 48.21 \\
\hline 1586 & 45.1 & 45.7 & 47.42 & 48.35 \\
\hline 1588 & 45.16 & 45.72 & 47.37 & 48.25 \\
\hline 1590 & 45.28 & 45.82 & 47.41 & 48.26 \\
\hline
\end{tabular}

Since the goal is to assess the pump wavelength dependency, the gain of the probe channel remains unchanged during the number of values. This is achieved by adjusting the pump power at different pump wavelengths to obtain the reference gain of the probe channel.

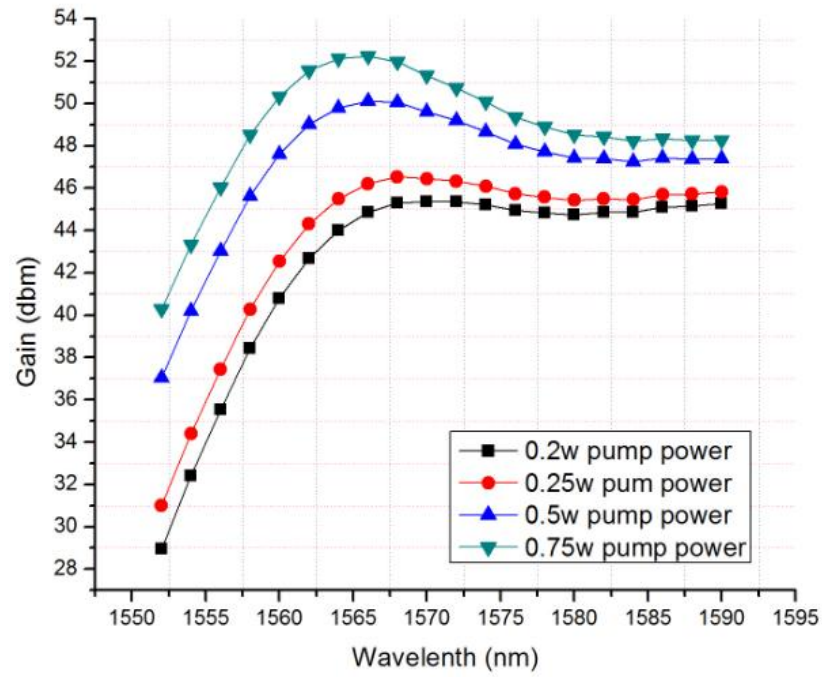

Figure 2: Gain Spectrum for different pump powers

Initially, a four-stage EDFA circuitry is designed by connecting four EDFAs in cascade in Opti system software. The Gain and Noise Figure for each and every Fiber circuitry is plotted and compared.

The four values of pump power that has been used are $0.2 \mathrm{~W}$, $0.25 \mathrm{~W}, 0.5 \mathrm{~W}$ and $0.75 \mathrm{~W}$ are shows in table 1-3 respectively. The Gain Spectrum, Noise Spectrum and the output signal to noise ratio have been found out for each of the respective pump powers. 
Table II: Noise Figure Spectrum for different pump powers

\begin{tabular}{|c|c|c|c|c|}
\hline Wavelength & \multicolumn{4}{|c|}{ Noise Figure (dbm) } \\
\hline $\mathrm{nm}$ & $\begin{array}{l}0.2 \mathrm{~W} \\
\text { pump } \\
\text { power }\end{array}$ & $\begin{array}{l}0.25 \mathrm{w} \\
\text { pump } \\
\text { power }\end{array}$ & $\begin{array}{l}0.5 \mathrm{w} \\
\text { pump } \\
\text { power }\end{array}$ & $\begin{array}{l}0.75 \mathrm{w} \\
\text { pump } \\
\text { power }\end{array}$ \\
\hline 1552 & 43.88 & 42.61 & 39.41 & 37.97 \\
\hline 1554 & 42.27 & 41.24 & 38.63 & 37.42 \\
\hline 1556 & 41.1 & 40.25 & 38.06 & 37.02 \\
\hline 1558 & 40.16 & 39.25 & 37.57 & 36.65 \\
\hline 1560 & 39.49 & 38.88 & 37.25 & 36.43 \\
\hline 1562 & 38.9 & 38.37 & 36.92 & 36.17 \\
\hline 1564 & 38.43 & 37.97 & 36.68 & 36.01 \\
\hline 1566 & 37.96 & 37.55 & 36.39 & 35.79 \\
\hline 1568 & 37.58 & 37.21 & 36.17 & 35.62 \\
\hline 1570 & 37.29 & 36.97 & 36.04 & 35.55 \\
\hline 1572 & 36.95 & 36.66 & 35.81 & 35.36 \\
\hline 1574 & 36.69 & 36.43 & 35.66 & 35.25 \\
\hline 1576 & 36.48 & 36.25 & 35.56 & 35.19 \\
\hline 1578 & 36.27 & 36.05 & 35.42 & 35.08 \\
\hline 1580 & 36.08 & 35.89 & 35.31 & 35 \\
\hline 1582 & 35.86 & 35.68 & 35.14 & 34.85 \\
\hline 1584 & 35.76 & 35.6 & 35.1 & 34.83 \\
\hline 1586 & 35.6 & 35.44 & 34.98 & 34.72 \\
\hline 1588 & 35.45 & 35.5 & 34.87 & 34.63 \\
\hline 1590 & 35.32 & 35.18 & 34.77 & 34.55 \\
\hline
\end{tabular}

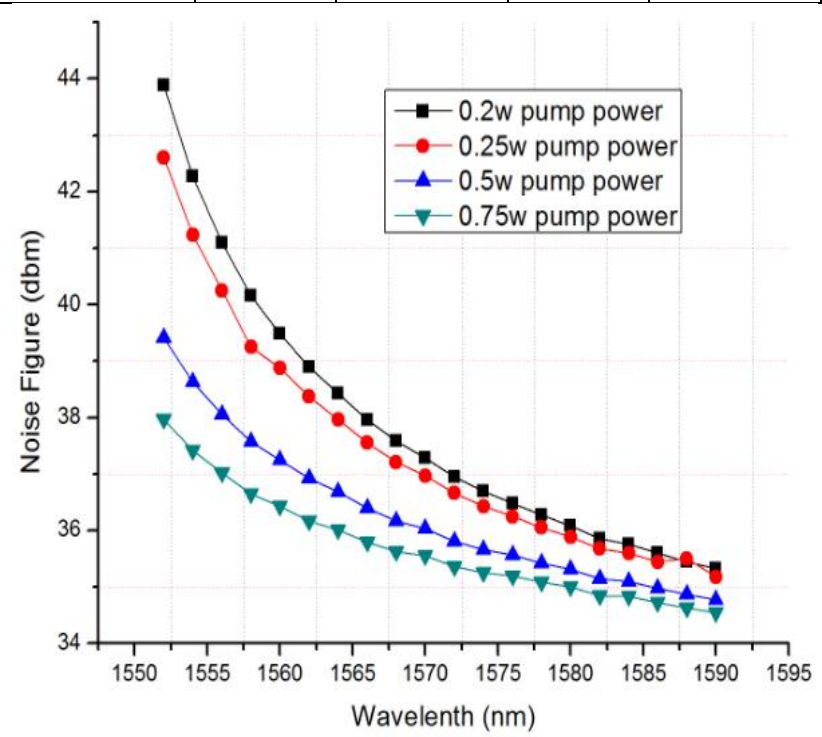

Figure 3: Noise Figure Spectrum for different pump powers

After comparing the Gain and Noise figure for pump powers $0.2 \mathrm{~W}, 0.25 \mathrm{~W}, 0.5$ and $0.75 \mathrm{~W}$ it has been found that, for pump power $0.75 \mathrm{~W}$ the best simulation results are obtained.

Table III: Optical SNR Spectrum for different pump powers

\begin{tabular}{|r|r|r|r|r|}
\hline \multicolumn{1}{|c|}{ Wavelength } & \multicolumn{4}{|c|}{ OSNR (dbm) } \\
\hline $\mathrm{nm}$ & $\begin{array}{c}0.2 \mathrm{w} \\
\text { pump } \\
\text { power }\end{array}$ & $\begin{array}{l}0.25 \mathrm{w} \\
\text { pump } \\
\text { power }\end{array}$ & $\begin{array}{c}0.5 \mathrm{w} \\
\text { pump } \\
\text { power }\end{array}$ & $\begin{array}{c}0.75 \mathrm{w} \\
\text { pump } \\
\text { power }\end{array}$ \\
\hline 1552 & 74.44 & 75.67 & 78.77 & 80.18 \\
\hline 1554 & 75.91 & 76.91 & 79.46 & 80.65 \\
\hline 1556 & 77.1 & 77.93 & 80.07 & 81.1 \\
\hline 1558 & 77.94 & 78.63 & 80.49 & 81.4 \\
\hline 1560 & 78.67 & 79.26 & 80.88 & 81.69 \\
\hline
\end{tabular}

\begin{tabular}{|r|r|r|r|r|}
\hline 1562 & 78.25 & 79.77 & 81.21 & 81.95 \\
\hline 1564 & 79.72 & 80.17 & 81.45 & 82.12 \\
\hline 1566 & 80.12 & 80.52 & 81.67 & 82.28 \\
\hline 1568 & 80.52 & 80.88 & 81.91 & 82.46 \\
\hline 1570 & 80.86 & 81.18 & 82.11 & 82.6 \\
\hline 1572 & 81.15 & 81.43 & 82.27 & 82.72 \\
\hline 1574 & 81.42 & 81.68 & 82.44 & 82.75 \\
\hline 1576 & 81.7 & 81.93 & 82.61 & 82.98 \\
\hline 1578 & 81.72 & 82.13 & 82.75 & 83.09 \\
\hline 1580 & 82.06 & 82.26 & 82.83 & 83.14 \\
\hline 1582 & 82.28 & 82.46 & 83 & 83.29 \\
\hline 1584 & 82.4 & 82.56 & 83.05 & 83.31 \\
\hline 1586 & 82.62 & 82.77 & 83.23 & 83.48 \\
\hline 1588 & 82.78 & 82.92 & 83.34 & 83.57 \\
\hline 1590 & 82.86 & 83 & 83.39 & 83.61 \\
\hline
\end{tabular}

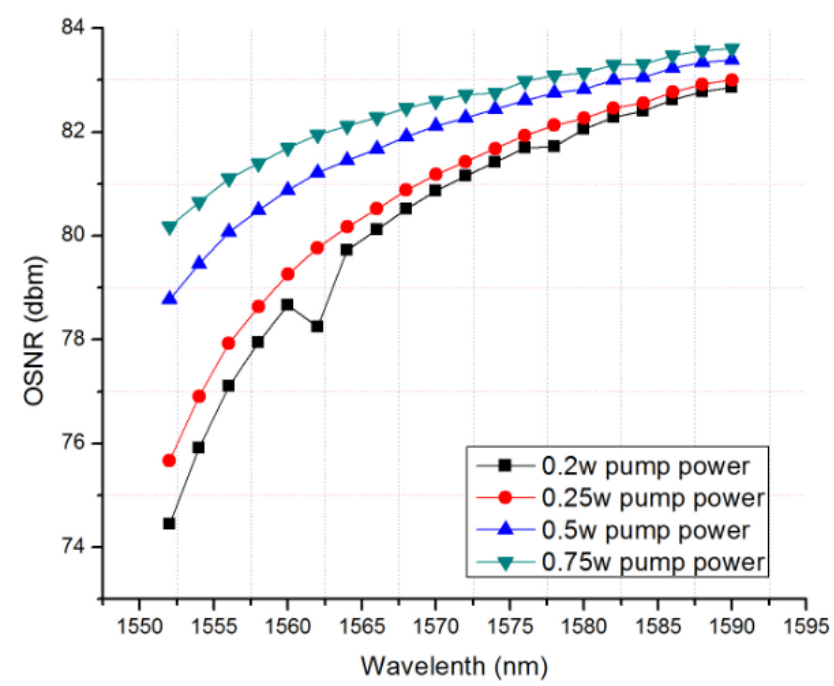

Figure 4: Noise Figure Spectrum for different pump powers

\section{CONCLUSION}

From the Optisystem, it is concluded that M-5 fiber is the most suitable fiber for the four-stage implementation of EDFA. The pump power was varied. Different Pump Powers like $0.2 \mathrm{~W}, 0.25 \mathrm{~W}, 0.5 \mathrm{~W}$ and $0.75 \mathrm{~W}$ were used. Analyzing the gain, optical signal to noise ratio and noise figure spectrum for the EDFA under different pump powers, it was concluded that the pump power of $0.75 \mathrm{~W}$ gives better results.

\section{ACKNOWLEDGMENT}

I express my profound sense of gratitude to Prof. manish Saxena, Department of Electronics and communication and Prof. Vineet Tiwari Department of Electronics and communication, BIST Bhopal for their useful suggestion and support.

\section{REFERENCES}

[1] Ricky Antony, "Performance analysis of different erbium doped fiber based directionally pumped wdm systems operating in optical wide-band" in International Journal of Engineering Science and Technology (IJEST), Vol. 4 No.02 February 2012.

[2] Sunil Kumar Panjeta, "Gain Optimization of of EDF Amplifier by stage enhancement and variation in pump power" in International Journal of Scientific and Research Publications, Volume 2, Issue 11, November 2012. 
[3] Mousami Biswas, "Modeling of Wide-Band Optical Signal Amplification in an EDFA Network" in PHOTONICS LETTERS OF POLAND, VOL. 4 (4), 158-160 (2012).

[4] Somnath Pain, "Gain Flattening and Noise Figure Analysis of EDFA WDM Configuration for L-band Optical Communication using Wavelength Selective Attenuator" in PHOTONICS LETTERS OF POLAND, VOL. 5 (3), 106-108 (2013)

[5] M A Mahdi, "Saturation parameters of erbium doped fibre amplifiers" in ICSE'98 Proc., Nov. 1998, Bangi, Malaysia.
[6] Usman J Sindhi "Performance analysis of 32-channel WDM System using EDFA" in IJEETC vol.2 no 2, April 2013.

[7] Farah Diana Binti, "Gain Optimization for WDM System" in Elektrika vol II no I, 2009.

[8] L. Rapp and G. Göger, "Effect of spectral hole burning on the feedforward control of erbium-doped fiber amplifiers," in Proc. Optical Fiber Communication Conf., San Diego, CA, Mar. 21-25, 2010, Paper OThI5.

[9] L. Rapp, "Transient behavior of EDFA stages using pump power splitting or pump bypass technique," $J$ Lightw. Technol., vol. 25, no. 3, pp. 726-732, Mar. 2007. 